\title{
HUMPHREY (Caroline), ONON (Urgunge), Shamans and Elders: Experience, Knowledge, and Power Among the Daur Mongols
}

Oxford, Clarendon Press, 1996, xiv+396 p. (bibliogr., cartes, illustr, index) (coll. « Oxford Studies in Social and Cultural Anthropology »)

\section{Françoise Aubin}

\section{(2) OpenEdition}

\section{Journals}

Édition électronique

URL : http://journals.openedition.org/assr/20900

DOI : 10.4000/assr.20900

ISSN : $1777-5825$

Éditeur

Éditions de l'EHESS

Édition imprimée

Date de publication : 1 juin 2001

Pagination : 141-142

ISBN : 2-222-96704-X

ISSN : 0335-5985

\section{Référence électronique}

Françoise Aubin, «HUMPHREY (Caroline), ONON (Urgunge), Shamans and Elders: Experience,

Knowledge, and Power Among the Daur Mongols ", Archives de sciences sociales des religions [En ligne],

114 | avril-juin 2001, document 114.82, mis en ligne le 19 août 2009, consulté le 21 septembre 2020.

URL : http://journals.openedition.org/assr/20900 ; DOI : https://doi.org/10.4000/assr.20900

Ce document a été généré automatiquement le 21 septembre 2020.

(C) Archives de sciences sociales des religions 


\section{HUMPHREY (Caroline), ONON (Urgunge), Shamans and Elders: Experience, Knowledge, and Power Among the Daur Mongols}

Oxford, Clarendon Press, 1996, xiv+396 p. (bibliogr., cartes, illustr, index) (coll. « Oxford Studies in Social and Cultural Anthropology »)

\section{Françoise Aubin}

\section{RÉFÉRENCE}

HUMPHREY (Caroline), ONON (Urgunge), Shamans and Elders: Experience, Knowledge, and Power Among the Daur Mongols, Oxford, Clarendon Press, 1996, xiv+396 . (bibliogr., cartes, illustr, index) (coll. « Oxford Studies in Social and Cultural Anthropology »)

1 U.O. est un Mongol du clan Onon d'une ethnie Daur (ou Dagour) qui parle un dialecte mongol archaïque et vit aux marges de la Mandchourie, dans une région soumise à l'occupation japonaise de 1932 à 1945, avant de tomber sous le régime communiste (cf. Arch. infra, 114.87). U.O. est connu pour avoir été mêlé de près à l'histoire de la Mongolie-Intérieure des années quarante: né fin 1919 selon le calendrier mongol traditionnel, ou le $1^{\mathrm{er}}$ janvier 1920 selon notre calendrier, il avait juste l'âge de profiter, en 1934, du système éducatif mis en place par les Japonais, puis de se former en sciences politiques à l'université de Tôkyô de 1941 à 1944, avant de mettre ses talents au service du prince Te (ou De, de son nom complet Demchugdonrub), le leader nationaliste de la Mongolie-Intérieure sous protection japonaise et après. Émigré aux États-Unis dans le sillage d'Owen Lattimore puis victime avec lui du McCarthisme, il le suit plus tard en Angleterre et fonde avec lui un département de chinois à Leeds, puis en 1968 un programme d'études mongoles; enfin, en 1985, il aide l'anthropologue 
mongolisante C.H. à établir à Cambridge une Unité d'Études de la Mongolie et de l'Asie centrale fort active depuis lors.

2 Il avait jadis narré, en une centaine de pages, quelques fraîches impressions de son enfance - My Childhood in Mongolia (Oxford University Press, 1972), livre devenu un classique de l'ethnologie mongole. Et voici que, quotidiennement ou presque, de 1987 à 1989, C.H. a eu la magnifique idée de le pousser à sortir du tréfonds de sa mémoire ses souvenirs les plus intimes, ceux ayant trait non pas à son expérience politique, mais à la conception du monde dans laquelle, enfant, il a baigné et qui l'a marqué à tout jamais, le chamanisme. Ses propos, suscités, recueillis, commentés et richement annotés par C.H., permettent de saisir le chamanisme - ou du moins la forme de chamanisme ayant cours chez les Daurs -, vu à la fois de l'intérieur par un usager consciemment engagé, et de loin, avec la distanciation requise par l'ethnologie. Par opposition aux logiques établies par les idéologies (le communisme par exemple) ou les religions (ainsi le bouddhisme), avec lesquels il cohabite aisément d'ailleurs, le chamanisme n'est pas imposé à une masse amorphe par la volonté d'une élite et il ne construit pas de classe sociale supérieure; il s'adresse à tous et doit son existence non à des textes concoctés par des lettrés, mais aux gens qui croient en lui et pour lesquels il unifie monde présent, nature et au-delà. Sans aucune distinction de supériorité par âge, ancienneté ou sexe, le chaman, dit yadgan en dagour, bénéficie d'une connaissance (medel) et d'une créativité émotive qui, exprimées par des poésies chantées, lui permettent d'identifier les esprits et la cause de leurs actions néfastes. Si divers de lieu à lieu et de peuple à peuple est le chamanisme dans ses pratiques et son mode de transmission de la connaissance des esprits, qu'il faut bien admettre que la généralité du terme de chamanisme est artificielle. Les trois cent cinquante pages d'un texte en typographie serrée se laissent lire allègrement, tant le récit est passionnant, bien articulé et nourri de découvertes. L'on apprend ainsi que les leaders révolutionnaires mongols du $\mathrm{XX}^{\mathrm{e}}$ siècle proviennent de régions chamanistes plus que bouddhistes. 